\title{
Mathematical Modeling of Physical System
}

\author{
Abhijit Patil ${ }^{1}$, Sangram More ${ }^{2}$ \\ ${ }^{1}$ ENTC,Symboisis Institute Of Technology, PUNE, INDIA) \\ ${ }^{2}$ (ENTC,Symboisis Institute Of Technology, PUNE, INDIA)
}

\begin{abstract}
In case of system Mathematical model plays an important role to give response. This paper explains different kinds of system such as electrical, mechanical, and hydraulic. In Accordance of it examples of Mechanical, Electrical and Hydraulic system are represented by mathematical model; in different types of Mathematical model i.e. Mechanical System by Differential Equation Model, Electrical system by State-Space Model and Hydraulic System by Transfer Function Model. Mathematical models of above systems are simulated by using MATLAB SIMULINK R2013a to check behaviour.
\end{abstract}

Keywords: Mathematical modeling, Electrical, Mechanical and Hydraulic systems and their behavior in Matlab.

\section{Introduction}

System is used to describe a combination of component which may be physical or may not. Mathematical model describes the system in terms of mathematical concept. The process of developing mathematical Model is known as Mathematical Modelling. Modelling is the process of writing a differential equation to describe a physical situation.

The basis for mathematical model is provided by the fundamental physical laws that govern the behaviour of system. It uses laws like Kirchhoff's law for electrical system, Newton's law for mechanical system.

Modelling of any system can help us to study effect of different of component and to make Prediction about Behaviour. Modelling can be divided into two parts i.e. First Principle Model and empirical model given in figure 1.

- First principle model that seeks to calculate a physical quantity starting directly from established laws of physics without making any assumptions.

Example-Electronic structure of atoms

- An Empirical modelling refers to any kind of modelling based on empirical observations rather than mathematically describable relationships of the system modelled.

Example- Tank System

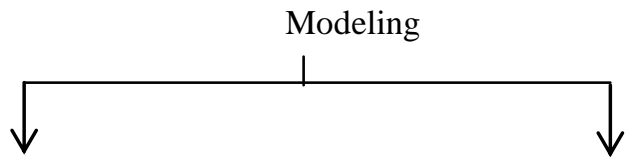

First Principle Model

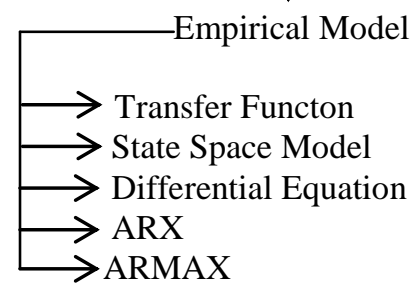

Figure1: Gives types and subtypes of modeling

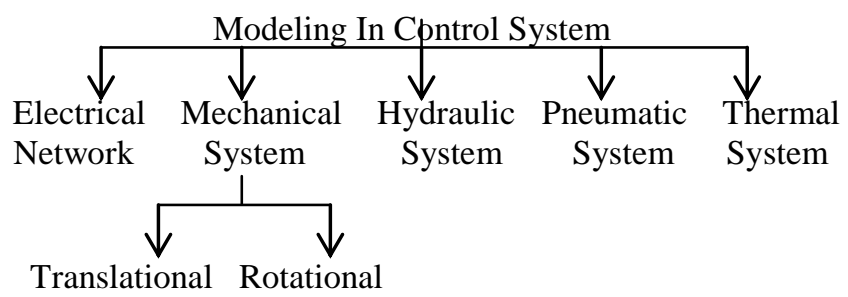

Figure 2: Types of control system are given in 


\section{Electrical System}

The Electrical System is made with element like Resistor, Capacitor and Inductor we can use mathematical modelling to check the behavior of any electrical system.

\section{Resistor:}

Resistor is a passive two-terminal electrical component that implements electrical resistance as a circuit element.

The current through a resistor is in direct proportion to the voltage across the resistor's terminals. This relationship is represented by Ohm's law:

$$
\mathrm{I}=\frac{\mathrm{V}}{\mathrm{R}}
$$

Where $I$ is the current through the conductor in units of amperes, $V$ is the potential difference measured across the conductor in units of volts, and $R$ is the resistance of the conductor in units of ohms.

The ratio of the voltage applied across a resistor's terminals to the intensity of current in the circuit is called its resistance, and this can be assumed to be a constant (independent of the voltage) for ordinary resistors working within their ratings.

\section{Capacitor:}

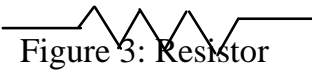

Capacitor is passive electrical component used to store energy electrostatically in an electric field. The forms of practical capacitors vary widely, but all contain at least two electrical conductors separated by a dielectric; for example, one common construction consists of metal foils separated by a thin layer of insulating film.

When there is a potential difference across the conductors, an electric field develops across the dielectric, causing positive charge to collect on one plate and negative charge on the other plate. Energy is stored in the electrostatic field.

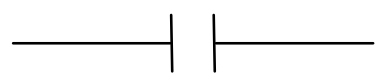

Voltage across Resistor given by

Figure 4: Capacitor

$$
\frac{1}{\mathrm{C}} \int \mathrm{I}_{\mathrm{C}} \mathrm{dt}
$$

\section{Inductor:}

An inductor is characterized by its inductance, the ratio of the voltage to the rate of change of current, which has units of Henry $(\mathrm{H})$. Many inductors have a magnetic core made of iron or ferrite inside the coil, which serves to increase the magnetic field and thus the inductance

\section{$M$}

Figure 5: Inductor

Current IL through inductor

$$
\frac{1}{\mathrm{~L}} \int \mathrm{E}_{\mathrm{L}} \mathrm{dt}
$$

\section{Example of Electrical System:-}

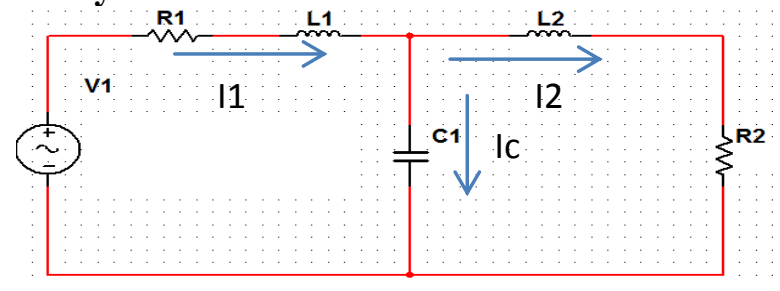

By applying KCL

$I_{C}=I_{1}-I_{2}$ 
$C \frac{d V}{d t}=I_{1}-I_{2}$

By applying KVL at Inductor 1

$$
\begin{aligned}
& V_{1}=R_{1} I_{1}+L_{1} \frac{d I_{1}}{d t}+V_{c} \\
& \frac{d I_{1}}{d t}=\frac{1}{L_{1}}\left(V-R_{1} I_{1}-V_{c}\right)
\end{aligned}
$$

By applying KVL at Inductor 2

$$
\begin{aligned}
& V_{c}=L_{2} \frac{d I_{2}}{d t}+R_{2} I_{2} \\
& \frac{d I_{2}}{d t}=\frac{1}{L_{2}}\left(V_{c}-R_{2} I_{2}\right)
\end{aligned}
$$

\section{State Space Representation}

$\left[\begin{array}{l}\mathrm{V}_{\mathrm{c}} \\ \mathrm{I}_{1} \\ \mathrm{I}_{2}\end{array}\right]=\left[\begin{array}{ccc}0 & \frac{1}{\mathrm{C} 1} & \frac{1}{\mathrm{C} 1} \\ -\frac{1}{\mathrm{~L} 1} & -\frac{\mathrm{R} 1}{\mathrm{C} 1} & 0 \\ \frac{1}{\mathrm{~L} 2} & 0 & \frac{\mathrm{R} 2}{\mathrm{~L} 2}\end{array}\right]\left[\begin{array}{l}\mathrm{V}_{\mathrm{c}} \\ \mathrm{I}_{1} \\ \mathrm{I}_{2}\end{array}\right]+\left[\begin{array}{c}0 \\ \frac{1}{\mathrm{~L} 1} \\ 0\end{array}\right]\left[\mathrm{V}_{\mathrm{i}}\right]$

$V_{O}=\left[\begin{array}{lll}0 & 0 & \mathrm{R} 2\end{array}\right]\left[\begin{array}{l}V_{c} \\ I_{1} \\ I_{2}\end{array}\right]$

Elements of Mechanical System

\section{Mechanical System}

\section{Mass:}

- A Force applied to the mass produces an acceleration of the mass.

- The reaction force $\mathrm{fm}$ is equal to the product of mass and acceleration and is opposite in direction to the applied force in term of displacement $y$, a velocity $\mathrm{v}$, and acceleration a, the force equation is

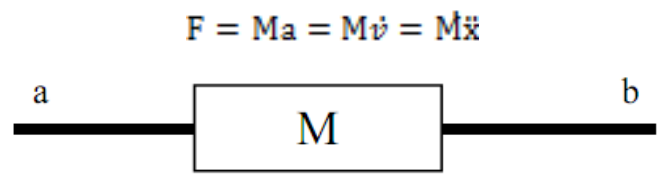

2. Spring:

Figure 6 : Mass

- The reaction force $\mathrm{F}$ on each end of the spring is the same and is equal to the product of stiffness $\mathrm{k}$ and the amount of deformation of the spring.

- End $\mathrm{C}$ has a position $\mathrm{Yc}$ and end D has a position $\mathrm{Yd}$ measured from the respective equilibrium positions. The force equation, in accordance with the Hok's law is

$$
\mathrm{F}=\mathrm{k}(\mathrm{Yc}-\mathrm{Yd})
$$

- If the end $\mathrm{D}$ is stationary, then $\mathrm{Yd}=0$ and the above equation reduces to $\mathrm{F}=\mathrm{kYc}$

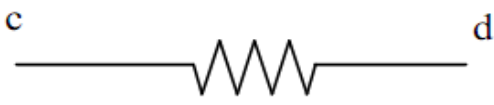

Figure 7 : Spring

\section{Damper:}

- The reaction damping force $F_{B}$ is approximated by the product of damping $B$ and the relative velocity of the two ends of the dashpot.

- The direction of this force depend on the relative magnitude and direction of the velocity Dye and Dyf

$\mathrm{F}_{\mathrm{b}}=\mathrm{B}\left(\mathrm{V}_{\mathrm{e}}-\mathrm{V}_{\mathrm{f}}\right)=\mathrm{B}\left(\mathrm{D}_{y_{\mathrm{s}}}-\mathrm{D}_{y_{\mathrm{f}}}\right)$ 


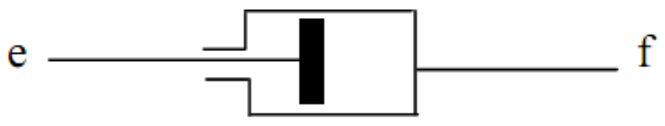

Figure 8 : Damper

\section{Mechanical System Example:-}

It is required to set up equation for system on application of force $F(t)$ to mass $m$. The resulting displacement of mass being $x$

Inirtial force $=\mathrm{M} \frac{\mathrm{d}^{2} \mathrm{x}}{\mathrm{dt}^{2}}$
Viscous Force $=\mathrm{f} \frac{\mathrm{dx}}{\mathrm{dt}}$
Spring Restoring Force $=\mathrm{Kx}$

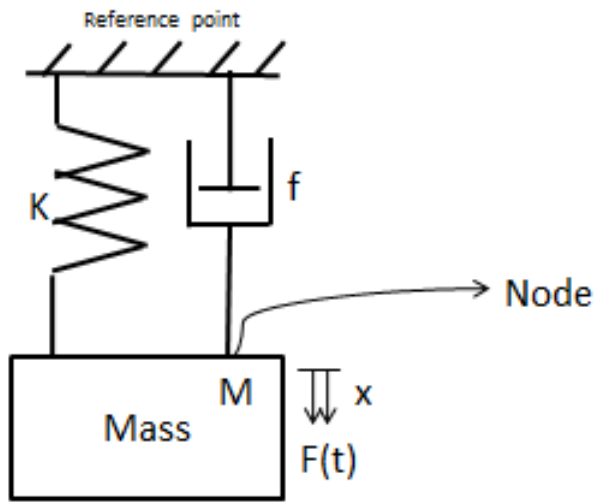

Figure 9: Example of Mechanical System

By applying Nodal Analysis we get

$$
\mathrm{M} \frac{\mathrm{d}^{2} \mathrm{x}}{\mathrm{dt}^{2}}+\mathrm{f} \frac{\mathrm{dx}}{\mathrm{dt}}+\mathrm{kx}=\mathrm{f}(\mathrm{t})
$$

By assuming initial condition are zero and taking Laplace transforms

$$
\mathrm{Ms}^{2} \mathrm{X}(\mathrm{s})+\mathrm{fs} \mathrm{X}(\mathrm{s})+\mathrm{kX}(\mathrm{s})=\mathrm{F}(\mathrm{s})
$$

Transform Equation can be given as

$$
\mathrm{G}(\mathrm{s})=\frac{1}{\mathrm{Ms}^{2}+\mathrm{fs}+\mathrm{K}}
$$

Elements of Hydraulic analogy

\section{Hydraulic System}

\section{Fluid Resistance:-}

- A construction in the bore of the pipe which requires more pressure to pass the same amount of water. All pipes have some resistance to flow, just as all wires have some resistance to current.

- Laminar Flow

$$
\mathrm{P}=\frac{1281 \mathrm{u}}{\pi \mathrm{D}^{4}} \mathrm{Q}=\mathrm{RQ} \quad \mathrm{R}=\frac{1281 \mathrm{u}}{\pi \mathrm{D}^{4}}
$$

For turbulent flow-

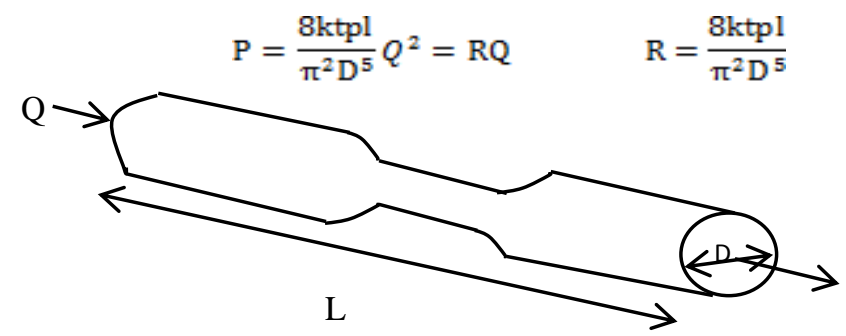

Figure 11: Flow of Liquid in Pipe 
l=length of pipe

$\mathrm{D}=$ diameter of pipe

$\mathrm{u}=$ viscosity

$\mathrm{Q}=$ volumetric flow rate

$\mathrm{Kt}=$ constant

$\mathrm{P}=$ mass density

\section{Fluid Capacitance:}

- The other element used in modeling fluid system is capacitance.

- In case when fluid is stored it carries potential energy act like a capacitor.

- Rate of fluid storage in Tank

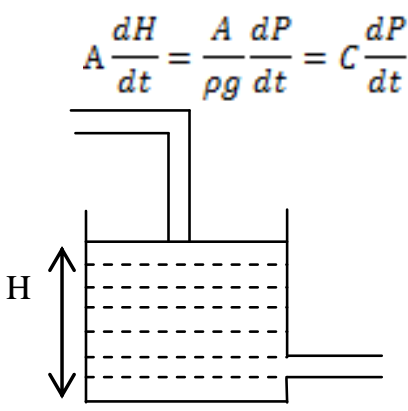

$\mathrm{H}=$ Height of liquid level

Figure 12: Fluid tank

$\mathrm{A}=$ Tank cross sectional area

$\mathrm{g}=$ Gravitational acceleration

$\mathrm{P}=$ Mass density

- Capacitance:

$$
C=\frac{A}{\rho g}
$$

\section{Fluid Inertance-}

- Inertial effect of fluid in pipe line is modeled as inertance.

- Change in Pressure of liquid in presence of inertance can be given as

$$
\Delta \mathrm{P}=\mathrm{L} \frac{\mathrm{dQ}}{\mathrm{dt}}
$$

- Inertance:

$$
L=\frac{p l}{A}
$$

4. Example of Hydraulic System:

Rate of fluid storage in a tank=

$$
\mathrm{A} \frac{\mathrm{dH}}{\mathrm{dt}}=\mathrm{C} \frac{\mathrm{dH}}{\mathrm{dt}}
$$

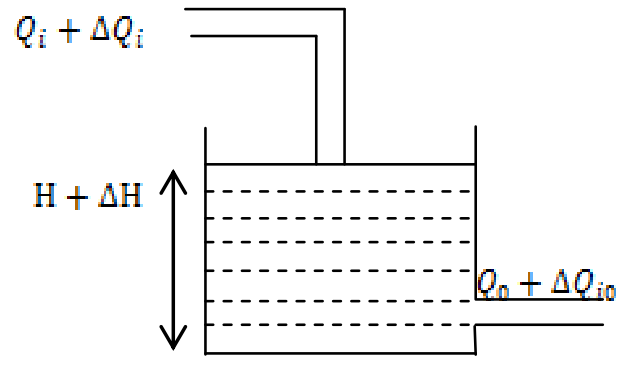

Figure 13 : Fluid Tank 
Under steady state condition

$\mathrm{Q}_{\mathrm{i}}=\mathrm{Q}_{0}$

Let $\Delta$ Qi be a small increase in liquid inflow rate from its steady state value this increased liquid inflow rate causes increase of head of liquid in tank by $\Delta \mathrm{H}$.Resulting increase of liquid outflow by

$\Delta \mathrm{Q}_{0}=\frac{\Delta \mathrm{H}}{\mathrm{R}}$

Rate of liquid storage in tank = Rate of liquid Inflow- Rate of liquid Outflow

$\mathrm{C} \frac{\mathrm{d} \Delta \mathrm{H}}{\mathrm{dt}}=\Delta \mathrm{Q}_{\mathrm{i}}-\Delta \mathrm{Q}_{\mathrm{O}}$

$\mathrm{C} \frac{\mathrm{d} \Delta \mathrm{H}}{\mathrm{dt}}=\Delta \mathrm{Q}_{\mathrm{i}}-\frac{\Delta \mathrm{H}}{\mathrm{R}}$

$\mathrm{RC} \frac{\mathrm{d} \Delta \mathrm{H}}{\mathrm{R}}+\Delta \mathrm{H}=\mathrm{R}\left(\Delta \mathrm{Q}_{\mathrm{i}}\right)$

By taking Laplace transform

Transfer Function:

$$
R C \cdot s H(s)+H(s)=R_{i}(s)
$$

$$
\frac{\mathrm{H}(\mathrm{s})}{\mathrm{Q}_{\mathrm{i}}(\mathrm{s})}=\frac{\mathrm{R}}{\mathrm{RC} \cdot \mathrm{s}+1}
$$

V. Matlab Simulation Of Each Part

1. Mass Spring Damper in Matlab Simulink By Differential Equation:

Model in Matlab Simulink

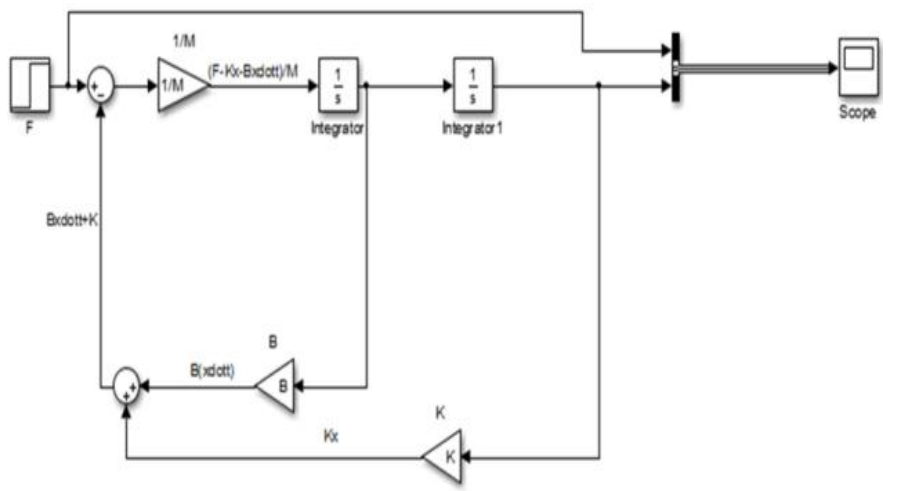

Select $M=10, B=2, K=5$

Figure 14 : Matlab Representation of Mechanical System

Time vs. Amplitude Of oscillation

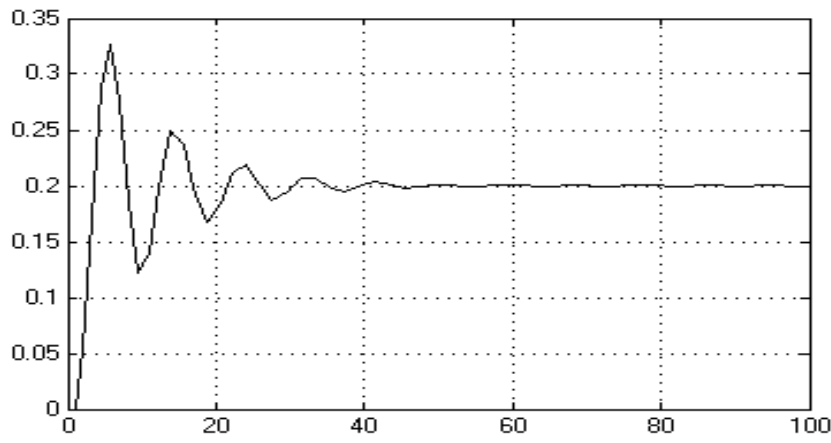

Figure 15: Behavior in Matlab 


\section{RLC In Matlab Simulink By State-Space Model:}

RLC Circuit Ex:

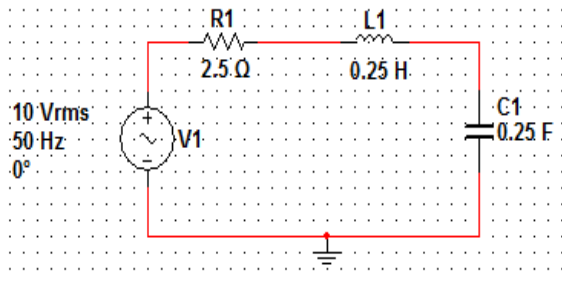

Figure 16 : RLC Circuit

Model in Matlab Simulink:

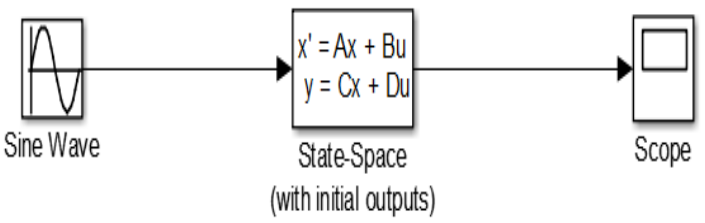

State-Space Matrix Values

Figure 17 : Matlab Representation of Electrical System

$A=\left[\begin{array}{cc}0 & 4 \\ 4 & -10\end{array}\right] \quad B=\left[\begin{array}{l}0 \\ 4\end{array}\right]$

$\mathrm{C}=\left[\begin{array}{lll}1 & 0\end{array}\right] \mathrm{D}=[0]$

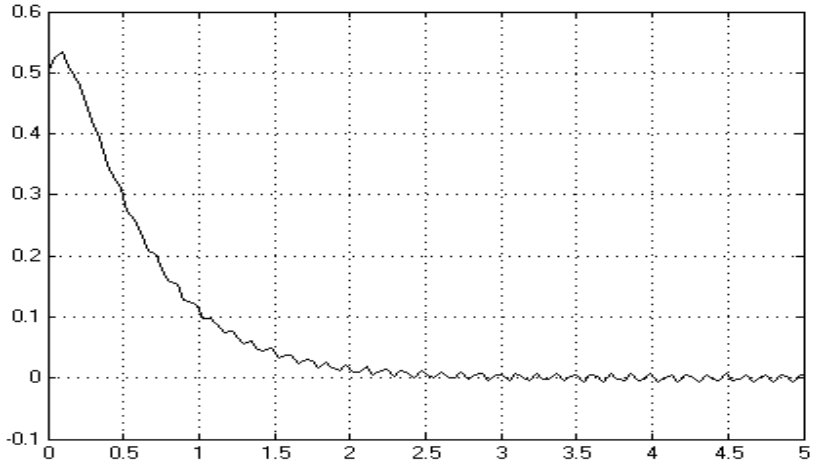

Figure 18: Behavior of RLC Circuit

\section{Tank System in Matlab Simulink by Transfer Function:}

Transfer Function for tank system can be given as

$$
\frac{\mathrm{H}(\mathrm{s})}{\mathrm{Q}_{\mathrm{i}}(\mathrm{s})}=\frac{\mathrm{R}}{\mathrm{RC} \cdot \mathrm{s}+1}
$$

Matlab Simulink Model

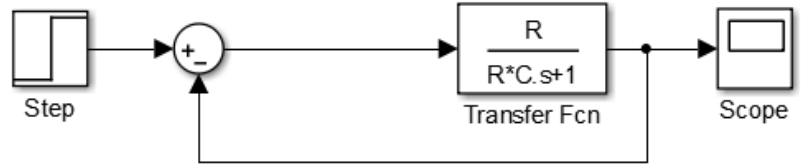

Figure 18 : Matlab Representation of Hydraulic System 
Simulate for different values of R and C and compare current and previous graph.

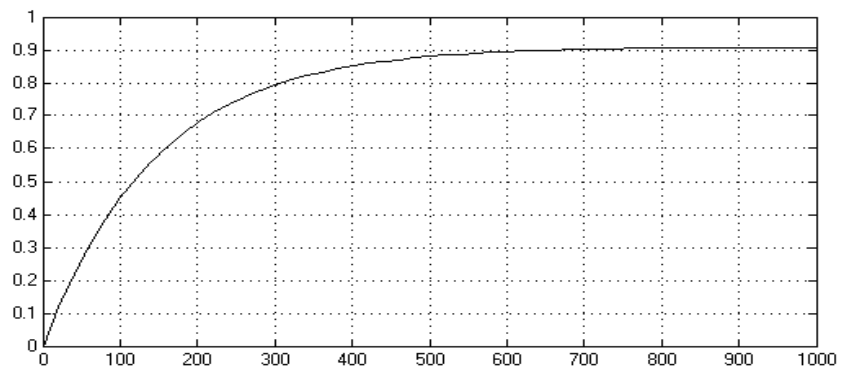

Figure 19: Behavior of Tank

\section{Conclusion}

In Order to understand the behaviour of systems, Mathematical Models are needed. These are simplified representations of certain aspects of real system. Such a model is created using equations to describe the relationship between input and output of system and can then be used to enable prediction to be made of the behaviour of a system under specific condition.

\section{References}

\section{Journal Papers:}

[1] Z. Zibo and F. Naghdy, "Application of Genetic Algorithms to System Identification," IEEE Int. Conf. On Evolutionary Computation, vol. 2, 1995, pp 777-787.

Books:

[1] Nagrath and Gopal, Control System Engineering.

[2] W. Bolton, Mechatronics, Pearson Publication.

[3] R.K. Bansal, Matlab and its application in engineering, Pearson Publication.

[4] Dr. Imtiaz Hussain ,Mathematical Modelling of Liquid Level Systems. 